\title{
Improving guideline adherence for cardiac rehabilitation in the Netherlands
}

\author{
H. M. C. Kemps • M. M. van Engen-Verheul • \\ R. A. Kraaijenhagen • R. Goud • I. M. Hellemans • \\ H. J. van Exel $•$ M. Sunamura $\cdot$ R. J. Peters $\cdot$ N. Peek
}

Published online: 13 April 2011

(C) The Author(s) 2011. This article is published with open access at Springerlink.com

\begin{abstract}
Background In 2004, the Netherlands Society of Cardiology released the current guideline on cardiac rehabilitation. Given its complexity and the involvement of various healthcare disciplines, it was supplemented with a clinical algorithm, serving to facilitate its implementation in daily practice. Although the algorithm was shown to be effective for
\end{abstract}

H. M. C. Kemps • M. M. van Engen-Verheul • I. M. Hellemans • N. Peek $(\bowtie)$

Department of Medical Informatics, Academic Medical Center, University of Amsterdam,

Room J1b-110, PO Box 22660, 1100 DD Amsterdam, the Netherlands

e-mail: N.B.Peek@amc.uva.nl

H. M. C. Kemps

Department of Cardiology, Máxima Medical Centre,

Veldhoven, the Netherlands

R. A. Kraaijenhagen

NDDO Institute for Prevention and Early Diagnostics (NIPED),

Amsterdam, the Netherlands

R. Goud

Gupta Strategists,

Ophemert, the Netherlands

H. J. van Exel

Rijnlands Rehabilitation Centre,

Leiden, the Netherlands

M. Sunamura

Capri Cardiac Rehabilitation,

Rotterdam, the Netherlands

R. J. Peters

Department of Cardiology, Academic Medical Center,

University of Amsterdam,

Amsterdam, the Netherlands improving guideline adherence, several shortcomings and deficiencies were revealed. Based on these findings, the clinical algorithm has now been updated. This article describes the process and the changes that were made.

Methods The revision consisted of three phases. First, the reliability of the measurement instruments included in the 2004 Clinical Algorithm was investigated by evaluating betweencentre variations of the baseline assessment data. Second, based on the available evidence, a multidisciplinary expert advisory panel selected items needing revision and provided specific recommendations. Third, a guideline development group decided which revisions were finally included, also taking practical considerations into account.

Results A total of nine items were revised: three because of new scientific insights and six because of the need for more objective measurement instruments. In all revised items, subjective assessment methods were replaced by more objective assessment tools (e.g. symptom-limited exercise instead of clinical judgement). In addition, four new key items were added: screening for anxiety/depression, stress, cardiovascular risk profile and alcohol consumption.

Conclusion Based on previously determined shortcomings, the Clinical Algorithm for Cardiac Rehabilitation was thoroughly revised mainly by incorporating more objective assessment methods and by adding several new key areas.

Keywords Cardiac rehabilitation · Clinical algorithm . Practice guidelines

\section{Introduction}

Cardiac rehabilitation (CR) is a multidisciplinary multifaceted intervention aiming at physical, psychological and social 
recovery of cardiac patients after a cardiac event or therapeutic intervention. Important secondary goals are to induce lifestyle changes and to improve medication adherence. Traditional indications for $\mathrm{CR}$ are related to coronary artery disease (CAD), including patients with myocardial infarction, angina pectoris and patients who underwent coronary artery bypass grafting or percutaneous transluminal coronary angioplasty. Previous studies showed that CR is highly effective in these patients, both in terms of improving quality of life and in reducing the risk of future events [1-3]. In the last decade, it has become clear that $\mathrm{CR}$ is not only beneficial for CAD patients but also for patients with chronic heart failure, congenital heart disease, arrhythmias, cardiac neurosis and patients who underwent heart transplantation, valvular surgery or implantable cardioverter defibrillator (ICD) implantation [4-7]. Because of this rise in referral indications and the increasing prevalence of cardiovascular patients due to ageing of our population, it is crucial that $\mathrm{CR}$ is widely available and well integrated in daily clinical practice.

In 2004, the Netherlands Society of Cardiology released the current CR guideline (Richtlijn Hartrevalidatie 2004) [8]. Given the complexity of this guideline and the involvement of many healthcare disciplines (cardiologist, nurse/nurse practitioner, physical therapist, dietician, social worker, medical psychologist, sports/rehabilitation physician), it was decided by the $\mathrm{CR}$ committee that a clinical algorithm had to be developed serving to aid healthcare professionals in implementing this guideline in daily practice. This clinical algorithm (Beslisboom Hartrevalidatie 2004) consists of a flowchart of questions on physical, psychological and social issues, using both measurement instruments (for example, the Shuttle walk test, MacNew heart disease health-related quality-of-life questionnaire $[9,10])$ and clinical judgment. The algorithm uses this information to set individual treatment goals and to advise the clinician on the contents of the CR programme, which may consist of four different group-based treatment modalities (exercise training, education therapy, lifestyle change therapy, and relaxation/stress management), and/or individual treatment.

Concurrent with the clinical algorithm, a computerised decision support system was developed, serving to facilitate the use of the clinical algorithm. This system (cardiac rehabilitation decision support system, CARDSS) actively guides its users through the clinical algorithm, prompting for necessary information and calculating scores of questionnaires. A recent trial in a cohort of 2,787 patients from 21 centres showed that CARDSS increases the compliance with guidelinerecommended therapeutic decisions [11]. However, this study also revealed shortcomings of the 2004 Clinical Algorithm, as illustrated by large variations in several baseline variables between hospitals, even after correction for differences in patient populations. Inter-practice variations were particularly large if assessments were based on clinical judgements rather than on clinical assessment instruments. Therefore, it was concluded that more measurement instruments are needed. Another shortcoming of the clinical algorithm was the deficiency of several items that have been shown to be relevant for CR (e.g. assessment of anxiety, depression and cardiac risk profile).

To overcome the mentioned shortcomings and deficiencies of the 2004 Clinical Algorithm and to further improve implementation of the Dutch CR guideline, the algorithm was recently updated. This article describes the process and the changes that were made and discusses its role in the development of CR in the Netherlands.

\section{Methods}

The revision of the 2004 Clinical Algorithm consisted of three phases. First, the reliability of the 2004 Clinical Algorithm was evaluated. As already mentioned, this was done by assessing inter-practice variations in the data recorded during the needs assessment procedure. In addition, cognitive, organisational and environmental barriers to guideline implementation were assessed by conducting interviews with healthcare professionals using CARDSS. The results of this study were described previously [12].

In the second phase, a multidisciplinary expert advisory panel was established, consisting of healthcare professionals who were involved in the development of the 2004 Dutch Cardiac Rehabilitation Guidelines. Members of this panel were instructed to select deficiencies and shortcomings needing revision from a list that was composed during the first phase. In addition, they were requested to provide specific recommendations for revision of these items based on available scientific evidence. The utility of clinical assessment instruments was evaluated by criteria developed by the Scientific Advisory Committee (SAC) of the Medical Outcomes Trust [13]. Finally, the expert advisory group was asked to propose new items that should be considered for inclusion in the Clinical Algorithm.

In the third phase, a guideline development group, consisting of members of all Dutch professional associations involved in $\mathrm{CR}$, decided which revisions proposed by the expert advisory group were finally included in the Clinical Algorithm 2010 [14]. In this phase, decisions were not only based on scientific evidence but also on applicability in daily clinical practice.

\section{Results}

Table 1 shows all shortcomings/deficiencies of the 2004 Clinical Algorithm that were selected during the revision process and the changes that were made in the 2010 
Table 1 Recommendations in the Clinical Algorithm 2004 and the revised recommendations in the Clinical Algorithm Cardiac Rehabilitation 2010 for all items in the five main domains of the needs assessment procedure

\begin{tabular}{|c|c|c|c|}
\hline Domain & Item & Clinical Algorithm 2004 & Clinical Algorithm 2010 \\
\hline \multirow[t]{2}{*}{$\begin{array}{l}\text { Physical } \\
\text { functioning }\end{array}$} & $\begin{array}{l}\text { Objective exercise } \\
\text { capacity }\end{array}$ & $\begin{array}{l}\text { Maximal symptom-limited exercise } \\
\text { test or clinical judgement }\end{array}$ & Maximal symptom-limited exercise test \\
\hline & $\begin{array}{l}\text { Subjective } \\
\text { exercise capacity }\end{array}$ & $\begin{array}{l}\text { MacNew quality-of-life questionnaire } \\
{[9,10] \text { or clinical judgement }}\end{array}$ & MacNew quality-of-life questionnaire $[9,10]$ \\
\hline \multirow[t]{3}{*}{$\begin{array}{l}\text { Psychological } \\
\text { functioning }\end{array}$} & $\begin{array}{l}\text { Emotional } \\
\text { functioning }\end{array}$ & $\begin{array}{l}\text { MacNew quality-of-life questionnaire } \\
{[9,10] \text { or clinical judgement }}\end{array}$ & MacNew quality-of-life questionnaire $[9,10]$ \\
\hline & $\begin{array}{l}\text { Anxiety/ } \\
\text { depression }\end{array}$ & Absent & $\begin{array}{l}\text { Hospital Anxiety and Depression Scale [25], } \\
\text { Patient Health Questionnaire [26] }\end{array}$ \\
\hline & Stress & Absent & Clinical interview (INTERHEART study) [27] \\
\hline \multirow[t]{3}{*}{$\begin{array}{l}\text { Social } \\
\text { functioning }\end{array}$} & Social functioning & $\begin{array}{l}\text { MacNew quality-of-life questionnaire } \\
{[9,10] \text { or clinical judgement }}\end{array}$ & MacNew quality-of-life questionnaire $[9,10]$ \\
\hline & Attitude of partner & Clinical interview, unstructured & Clinical interview, structured (3 questions) \\
\hline & Work resumption & Clinical interview, unstructured & $\begin{array}{l}\text { Clinical interview, structured ( } 2 \text { to } 7 \text { questions, } \\
\text { two-stage screening) }\end{array}$ \\
\hline $\begin{array}{l}\text { Cardiovascular } \\
\text { risk profile }\end{array}$ & $\begin{array}{l}\text { Cardiovascular } \\
\text { risk profile }\end{array}$ & Absent & Assessment of cardiovascular risk factors \\
\hline \multirow[t]{4}{*}{ Risk behaviour } & Smoking status & Clinical interview, structured & $\begin{array}{l}\text { Clinical interview, structured and specific } \\
\text { treatment advice }\end{array}$ \\
\hline & Physical activity & Clinical interview, unstructured & Monitor 'Physical Activity and Health' [28] \\
\hline & Dietary habits & Clinical interview, unstructured & Individual screening by dietician on indication \\
\hline & $\begin{array}{l}\text { Alcohol } \\
\text { consumption }\end{array}$ & Absent & Five Shot questionnaire $[29,30]$ \\
\hline
\end{tabular}

version. A total of nine items were revised. Three items were changed because of new insights provided by more recent CR guidelines, and six items were revised because of significant between-centre variation of the baseline assessment data in the 2004 algorithm [15]. For example, after correction for differences in patient populations, the mean percentage of patients with a psychological problem ranged from $17 \%$ to $37 \%$ when assessed by clinical interview, as compared with ranging from $54 \%$ to $59 \%$ when assessed by the MacNew questionnaire. This indicates that assessment by clinical interview not only results in a larger betweencentre variation but also in an underestimation and, consequently, to undertreatment of psychological problems. The latter problem also exists when looking at estimation of exercise capacity: The assessment of patients' exercise capacities by clinical interview led to a lower percentage of patients being judged as having an insufficiency than when bicycle ergometry or incremental Shuttle walk test was used ( $73 \%$ vs. $84 \%, p<0.01)$. In all revised items, subjective assessment methods (clinical experience or unstructured clinical interview) were replaced by more objective assessment tools. In addition, based on new scientific insights, the multidisciplinary expert advisory panel added four new key items to the 2010 algorithm: screening for anxiety/depression, stress, cardiovascular risk profile and alcohol consumption.

\section{Discussion}

The benefit of physical activity for cardiac patients was already noted more than 200 years ago [16]. However, it was not until the 1960s that CR programmes were gradually implemented in clinical practice [17]. In 1965, the Netherlands Heart Foundation and Netherlands Society of Cardiology formed a committee on CR. At that time, the main focus of $\mathrm{CR}$ was on physical reconditioning and work resumption. In the early 1990s, a broader and more versatile view on CR was gradually developed. Based on these new insights, the CR committee released the first Dutch CR guideline in 1995. In addition to exercise training, the $\mathrm{CR}$ programme also comprised education therapy and psychoeducative prevention therapy (PEP module). In 2004, this guideline was replaced by the current Dutch CR guideline, which gives more attention to risk prevention through behavioural changes (e.g. smoking cessation, increasing physical activity, improving dietary habits) as well as to psychosocial recovery. In addition, several new diagnosis groups were included (patients with chronic heart failure, congenital heart disease, patients who underwent heart transplantation or ICD implantation and elderly patients). The number of possible treatment modalities was extended to four group-based interventions (exercise training, education therapy, lifestyle change therapy and relaxation / stress management) and, in selected cases, additional individual 
treatment (e.g. by psychologist or dietician). In 2008, the Netherlands Society of Cardiology instituted a project group to revise the Dutch guideline with respect to psychosocial and work-related aspects of CR (PAAHR project). It is expected that the revised guideline will be released later this year.

A general problem with guidelines for cardiovascular disease, and in particular when guidelines are complex and multidisciplinary such as in cardiac rehabilitation, is that physician adherence is often poor [18, 19]. This lack of adherence may be related to insufficient knowledge, the physicians' attitude (e.g. a lack of agreement with the guideline, a lack of outcome expectancy and/or a lack of motivation) or to the presence of external barriers (e.g. lack of resources, insufficient reimbursement or organisational constraints) [20]. Whereas it is difficult to overcome external barriers, several strategies have been advocated to improve the physicians' knowledge and motivation. One of the most frequently used intervention strategies is education. However, previous studies showed only moderate effects of educational outreach by experts or trained facilitators. Yet, this effect can be increased by providing feedback and reminders to professionals [21]. As such, clinical decision aids have been shown to be effective in improving guideline adherence, mainly by increasing knowledge, reducing the tendency to stick to previous practice and by reducing guideline complexity [22, 23]. Therefore, given its complex and multidisciplinary nature, $\mathrm{CR}$ is particularly suitable for the use of clinical decision aids such as a clinical algorithm. In addition to a cardiologist, the CR team consists of a coordinator (e.g. nurse, nurse practitioner or physician assistant), a physical therapist, a dietician, a social worker and in selected cases a medical psychologist, a sports physician and/or a rehabilitation physician. As individual patients may need different combinations of treatments from different healthcare professionals from the CR team, a clinical algorithm can be a useful and efficient tool to delegate tasks and responsibilities.

In order to be effective for improving guideline adherence, a clinical algorithm should include well-defined, nonambiguous procedures for assessing the rehabilitation needs for individual patients. Therefore, the main focus of the present study was to include more objective measurement instruments as compared with the 2004 Clinical Algorithm. As current $\mathrm{CR}$ guidelines do not provide specific measurement instruments, a multidisciplinary expert advisory panel was established to elect these instruments, using specified (SAC) criteria for its evaluation [13]. Although this approach has been implemented successfully previously [24], the effect of the updating procedure on inter-practice variation of variables obtained during the needs assessment procedure, as well as on guideline adherence, is yet to be investigated. In addition to improving guideline adherence, the updated
Clinical Algorithm may also serve to improve the quality of $\mathrm{CR}$ in the Netherlands; by registering data through a computerised decision support system incorporating the Clinical Algorithm, knowledge on barriers to the implementation of CR can be expanded, and implementation strategies can be improved. Furthermore, these data can provide benchmark information for improving quality in individual CR centres.

Notwithstanding the fact that using a clinical algorithm in general is an effective strategy to improve guideline adherence, it may not always be successful. This is particularly the case when external barriers play an important role, such as organisational or procedural changes that are beyond the tasks and responsibilities of the healthcare professionals. Also, it should be acknowledged that the application of a clinical algorithm is only one among several strategies that can be used to improve adherence to $\mathrm{CR}$ guidelines. It may be even more effective when incorporating other strategies, such as educational outreach visits to healthcare professionals. Additional interventions may also be aimed at the patient, e.g. by providing all eligible patients (web-based) information at discharge to improve insight into disease severity, risk behaviour and follow-up plans.

\section{Conclusion}

Although the 2004 Dutch Clinical Algorithm for assessing patient needs in Cardiac Rehabilitation was shown to be effective for improving compliance with guidelinerecommended therapeutic decisions, several shortcomings and deficiencies were revealed. Therefore, a thorough revision was performed according to the latest scientific insights, using more objective assessment instruments. The new clinical algorithm (Beslisboom Poliklinische Indicatiestelling Hartrevalidatie 2010) [14] provides an efficient decision procedure to delegate tasks and responsibilities to healthcare professionals active in the field of CR.

Acknowledgement The authors gratefully thank the following members of the Committee for Cardiovascular Prevention and Rehabilitation of the Netherlands Society of Cardiology for their contributions to the development of the 2010 Clinical Algorithm: Dr J. Brügemann (UMC Groningen), Prof. Dr. A.P.M. Gorgels, J.M.C. van Hal (Slingeland Hospital Doetinchem), W.J. Louridtz (Isala Klinieken, Zwolle), P. van Schaardenburg (Catharina Hospital Eindhoven), N.H. M.K. Uszko-Lencer (AZM, Maastricht) and Dr. M.E. Wittekoek (Cardiologie Centra Nederland, Almere). Also we would like to thank the members of the National Multidisciplinary Assembly on Cardiac Rehabilitation.

Open Access This article is distributed under the terms of the Creative Commons Attribution Noncommercial License which permits any noncommercial use, distribution, and reproduction in any medium, provided the original author(s) and source are credited. 


\section{References}

1. Jolliffe JA, Rees K, Taylor RS, et al. Exercise-based rehabilitation for coronary heart disease. Cochrane Database Syst Rev. 2001; CD001800.

2. Suaya JA, Stason WB, Ades PA, et al. Cardiac rehabilitation and survival in older coronary patients. J Am Coll Cardiol. 2009;54:25-33.

3. Taylor RS, Brown A, Ebrahim S, et al. Exercise-based rehabilitation for patients with coronary heart disease: systematic review and metaanalysis of randomized controlled trials. Am J Med. 2004;116:682-92.

4. Piepoli MF, Davos C, Francis DP, et al. Exercise training metaanalysis of trials in patients with chronic heart failure (ExTraMATCH). BMJ. 2004;328:189.

5. Brugemann J, Postema K, van Gelder IC, et al. Cardiac rehabilitation in patients with a congenital heart disease, an implantable cardioverter defibrillator or chronic heart failure. Ned Tijdschr Geneeskd. 2004;148:1809-15.

6. Butchart EG, Gohlke-Barwolf C, Antunes MJ, et al. Recommendations for the management of patients after heart valve surgery. Eur Heart J. 2005;26:2463-71.

7. Kavanagh T, Mertens DJ, Shephard RJ, et al. Long-term cardiorespiratory results of exercise training following cardiac transplantation. Am J Cardiol. 2003;91:190-4.

8. Revalidatiecommissie Nederlandse Vereniging Voor Cardiologie/ Nederlandse Hartstichting. Richtlijn Hartrevalidatie 2004. The Hague: Netherlands Heart Foundation; 2004.

9. de Gucht V, van Elderen T, van der Kamp L, et al. Quality of life after myocardial infarction: translation and validation of the MacNew Questionnaire for a Dutch population. Qual Life Res. 2004;13:1483-8.

10. Dixon T, Lim LL, Oldridge NB. The MacNew heart disease health-related quality of life instrument: reference data for users. Qual Life Res. 2002;11:173-83.

11. Goud R, de Keizer NF, ter Riet G, et al. Effect of guideline based computerised decision support on decision making of multidisciplinary teams: cluster randomised trial in cardiac rehabilitation. BMJ. 2009;338:b1440.

12. Goud R, van Engen-Verheul M, de Keizer NF, et al. The effect of computerized decision support on barriers to guideline implementation: a qualitative study in outpatient cardiac rehabilitation. Int $\mathbf{J}$ Med Inform. 2010;79:430-7.

13. Anonymous. Assessing health status and quality-of-life instruments: attributes and review criteria. Qual Life Res. 2002;11:193-205.

14. Nederlandse Vereniging Voor Cardiologie. Beslisboom Poliklinische Indicatiestelling Hartrevalidatie 2010. Utrecht: NVVC, 2010. Also available at: http://www.nvvc.nl/media/richtlijn/95/Beslisboom\% 20Poliklinische $\% 20$ Indicatiestelling\%20Hartrevalidatie\%202010.pdf

15. Goud R. Computerized decision support to improve guideline implementation in cardiac rehabilitation; The CARDSS Project [thesis]. Amsterdam: University of Amsterdam, 2009. 2009. Also available at: http://dare.uva.nl/document/136472

16. Heberden W. Some accounts of a disorder of the chest. Med Trans Coll Physician. 1772;2:59.

17. Certo CM. History of cardiac rehabilitation. Phys Ther. 1985;65:1793-5.

18. Bjarnason-Wehrens $\mathrm{B}$, McGee $\mathrm{H}$, Zwisler $\mathrm{AD}$, et al. Cardiac rehabilitation in Europe: results from the European Cardiac Rehabilitation Inventory Survey. Eur J Cardiovasc Prev Rehabil. 2010;17:410-8.

19. Mazzini MJ, Stevens GR, Whalen D, et al. Effect of an American Heart Association Get With the Guidelines program-based clinical pathway on referral and enrollment into cardiac rehabilitation after acute myocardial infarction. Am J Cardiol. 2008;101:1084-7.

20. Cabana MD, Rand CS, Powe NR, et al. Why don't physicians follow clinical practice guidelines? A framework for improvement. JAMA. 1999;282:1458-65.

21. Grol R, Grimshaw J. From best evidence to best practice: effective implementation of change in patients' care. Lancet. 2003;362: 1225-30.

22. Garg AX, Adhikari NK, McDonald H, et al. Effects of computerized clinical decision support systems on practitioner performance and patient outcomes: a systematic review. JAMA. 2005;293:1223-38.

23. Kawamoto K, Houlihan CA, Balas EA, et al. Improving clinical practice using clinical decision support systems: a systematic review of trials to identify features critical to success. BMJ. 2005;330:765.

24. National Institute for Health and Clinical Excellence (NICE). Updating clinical guidelines and correcting errors. The guidelines manual. London: National Institute for Health and Clinical Excellence; 2009. p. 142-7.

25. Spinhoven P, Ormel J, Sloekers PP, et al. A validation study of the Hospital Anxiety and Depression Scale (HADS) in different groups of Dutch subjects. Psychol Med. 1997;27:363-70.

26. Spitzer RL, Kroenke K, Williams JB. Validation and utility of a self-report version of PRIME-MD: the PHQ primary care study. Primary Care Evaluation of Mental Disorders. Patient Health Questionnaire. JAMA. 1999;282:1737-44.

27. Rosengren A, Hawken S, Ounpuu S, et al. Association of psychosocial risk factors with risk of acute myocardial infarction in 11119 cases and 13648 controls from 52 countries (the INTERHEART study): case-control study. Lancet. 2004;364:953-62.

28. Douwes M, Hildebrandt VH. Questions on the amount of physical activity. Geneeskd Sport. 2000;33:9-16.

29. De Rick A, Vanheule S. Pilot study: does the Five Shot Questionnaire give an indication of the severity of alcohol use-related problems? Subst Use Misuse. 2007;42:1593-601.

30. Seppa K, Lepisto J, Sillanaukee P. Five-shot questionnaire on heavy drinking. Alcohol Clin Exp Res. 1998;22:1788-91. 